\title{
A STUDY OF ASSOCIATION BETWEEN BIRTH SEASONALITY, BIRTH ORDER AND SPACING IN SCHIZOPHRENIC PATIENTS
}

\author{
M. Arun Venkatesh ${ }^{1}$
}

${ }_{1}^{1}$ Assistant Professor, Department of Psychiatry, Government Sivagangai Medical College, Tamilnadu.

ABSTRACT
BACKGROUND
Schizophrenia is a major psychiatric illness characterised mainly by abnormal thinking as well as changes in mood and perception.
Western studies tell that Schizophrenics are born in monsoon contrary to Indian studies. The same controversy exists with birth
order and spacing. This study illustrates the strong association of season, birth order and spacing in schizophrenia patients.

\section{MATERIALS AND METHODS}

A case control study with exploratory design of medium sized sampling $(n=40) .40$ cases diagnosed as Schizophrenics using ICD10 criteria with patient's healthy attenders, preferably siblings serve as controls. Data such as birth season, birth spacing and order well known to attenders are included for the study.

\section{RESULTS}

The results obtained are put in tables and the variables are compared among cases and controls by angle of dispersion, parame tric and non-parametric tests.

\section{CONCLUSION}

The results are in agreement in most of Indian studies, viz. Winter births, higher birth order and low birth spacing is common in schizophrenic patients.

\section{KEYWORDS}

Schizophrenia- Association with Season- Birth Order and Spacing- Case Control Study.

HOW TO CITE THIS ARTICLE: Venkatesh MA. A study of association between birth seasonality, birth order and spacing in schizophrenic patients. J. Evolution Med. Dent. Sci. 2018;7(05):550-552, DOI: 10.14260/jemds/2018/124

\section{BACKGROUND}

Schizophrenia is a disorder characterised by severe disturbances in patient's activity, behaviour, perceptual disturbances as well as affective symptoms. It results from a combination of brain vulnerability, life events, factors such as birth order, spacing, genes, maternal stress, viral infections, oestrogen, middle ear disease and seasonality are studied. Epidemiologic studies say schizophrenics are more likely to have been born in winter and spring- prenatal folate deficiency is implicated as a causative factor in schizophrenia based on which Luc Smits ${ }^{1}$ et al says that short birth intervals are associated with high risk for Schizophrenia.

Torrey et $\mathrm{al}^{2}$ (1997) reviewed over 250 states from 29 countries and 5 from southern hemisphere concerning relation between birth seasonality and schizophrenia. There is $5 \%-8 \%$ increase in mental disorder in individuals born between Dec - May. A systematic review and meta-analysis of northern Hemisphere by Davis et $\mathrm{al}^{3}$ winter/ spring vs. summer/ autumn births were compared and a significant excess of winter/ spring births were found. The pooled Odds Ratio $=1.07,95 \%$ confidence interval $1.05-1.08$. Attributable risk $=3.3 \%$.

In southern hemisphere, a study by Berk $\mathrm{M}$ et al showed a significant peak in late spring and early summer.

'Financial or Other Competing Interest': None.

Submission 22-12-2017, Peer Review 13-01-2018,

Acceptance 22-01-2018, Published 29-01-2018.

Corresponding Author:

Dr. M. Arun Venkatesh,

Plot No. 2, Subramania Siva Street,

Nehru Nagar, Madurai-10.

E-mail: arunvenkat1973@gmail.com

DOI: $10.14260 /$ jemds $/ 2018 / 124$

\section{(c) (i) $(5$}

In an Indian study by Rakesh Kumar, in 380 Schizophrenic patients with 685 controls revealed an excess of winter births by $6.1 \%$.

Maternal third trimester infections (influenza in winter) or Vit-D deficiency due to reduced sunlight which decrease amplitude of maternal circadian.

Pacemaker, decreased melatonin concentration and increased core body temperature have detrimental effects in immature brain dysfunction causes decreased extracellular dopamine and increased phasic dopamine release, the characteristic biochemical lesion in Schizophrenia.

\section{Review of Literature}

The age differences between siblings have been suggested as a risk factor for schizophrenia. Luc Smits et al $^{1}$ investigated age differences between sibs of 5095 cases as compared to intervals of 45 months and schizophrenic ratio of 1.14 for birth intervals up to 15 months, 1.32 for $15-17 \mathrm{~m}, 1.38$ for $18-20 \mathrm{~m}, 1.13$ for $21-26 \mathrm{~m}$ with the results. Smits et al showed association between short birth intervals and schizophrenia.

Gunaverdana et $\mathrm{al}^{4}$ in a longitudinal, population-based cohort, the risk of schizophrenia increased by $150 \%$ in those births following a birth interval less than 6 months. They found folate deficiency may be an important risk factor for schizophrenia.

Sorensan et al ${ }^{5}$ with maternal $\mathrm{h} / \mathrm{o}$ anaemia, the diagnosis of anaemia during pregnancy had 1.6 folds (95\% confidence interval of 1.16 - 2.15) increased risk of schizophrenia due to iron deficiency.

Jari K Haukka and Suvisaari ${ }^{6}$ in their case of sibling study showed that persons with schizophrenia were one of the first 
3 siblings in birth order. They come to inclusion that birth spacing is not a major risk factor in schizophrenia.

\section{MATERIALS AND METHODS}

The aim of this study is to analyse birth seasonality, birth order and spacing in schizophrenic patients in Tirunelveli Medical College Hospital confirmed using ICD-10 criteria from Jan - Mar 2013.

\section{Study Design}

An observational case control analytical study depending on availability of cases and time required, comparing birth season, order, spacing of 40 cases with 40 controls with patients diagnosed as schizophrenics using ICD-10 criteria during the period from Jan - Mar 2013 with patient's attenders serving as controls.

\section{Statistical Design}

Odds ratio, non-parametric chi-square tests are employed.

\section{Inclusion Criteria}

1. All schizophrenic patients with florid symptoms and their attenders capable of giving necessary information.

2. Cooperative patients with reliable attender.

3. Cases who are diagnosed as schizophrenia with significant phenomenology using ICD-10 criteria.

\section{Exclusion Criteria}

1. Patients with deficit state.

2. Uncooperative patients.

3. Severely illiterate siblings and attenders not able to tell birth history.

4. Mentally retarded and substance-induced psychosis.

Cases are a group of patients having disease in a defined study population. In this study diagnosed as having Schizophrenia by ICD-10 criteria.

Controls are group of individuals not having the disease from the same population and independent of exposure.

\section{Selection of Controls and Cases}

Controls are selected from the same family (attenders, preferably siblings) and independent of exposure. Cases are selected as Schizophrenics using ICD-10 criteria from source population who are having florid symptoms. Residual schizophrenics are not taken for study.

\section{Tools Used}

Semi-structured proforma for socio-demographic profile.

\section{Proforma Content}

Factors such as name, age, sex, education, occupation, place, age at presentation of illness, birth order in family, spacing, seasonality, family history and other medical illness.

\section{RESULTS}

\begin{tabular}{|c|c|c|}
\hline Birth Season & $\begin{array}{c}\text { Gen Population } \\
\text { No. and \% }\end{array}$ & $\begin{array}{c}\text { Schizophrenia } \\
\text { No. and \% }\end{array}$ \\
\hline Winter (Nov-Feb) & 1025 & 1640 \\
\hline Summer (Mar-Jun) & 1025 & 1230 \\
\hline Monsoon (Jul-Oct) & 2050 & 1230 \\
\hline Table 1. Showing Association between \\
Schizophrenia and Season \\
\hline
\end{tabular}

There is an increase in $15 \%$ winter births among schizophrenics vs. general population. Increase in 5\% of summer births among schizophrenics vs. general population. Decrease in $20 \%$ in monsoon births in schizophrenics vs. general population.

\section{Odds Ratio}

The odds ratio of schizophrenics is being winter born 2.00 with $95 \%$ confidence interval 0.62 - 5.05. Odds ratio for monsoon births of schizophrenic born is 0.43 with $95 \%$. Confidence interval being in the range of $0.15-1.18$.

\begin{tabular}{|c|c|c|c|}
\hline $\begin{array}{c}\text { Age Group } \\
\mathbf{2 0 - 3 0}\end{array}$ & $\begin{array}{c}\text { Schizo } \\
\text { No. 12 }\end{array}$ & $\begin{array}{c}\text { Schizo } \\
\mathbf{3 0}\end{array}$ & $\begin{array}{c}\text { Winter Births } \\
\mathbf{2 8}\end{array}$ \\
\hline $30-40$ & 20 & 50 & 30 \\
\hline $40-50$ & 8 & 20 & 50 \\
\hline \multicolumn{4}{|c|}{ Table 2. Showing Age Group of Onset of Schizophrenia } \\
\hline
\end{tabular}

\begin{tabular}{|c|c|c|}
\hline Birth Order & No. of Cases & \% \\
\hline $1^{\text {st }}$ child & 12 & 30 \\
\hline $2^{\text {nd }}$ child & 12 & 30 \\
\hline $3^{\text {rd }}$ child & 8 & 20 \\
\hline $4^{\text {th }}$ child & 6 & 15 \\
\hline $5^{\text {th }}$ child & 2 & 5 \\
\hline
\end{tabular}

Table 3. Showing Relation between Birth Order and Cases

\begin{tabular}{|c|c|c|}
\hline Birth Interval & No. of Cases & $\mathbf{\%}$ \\
\hline $10-17$ & 10 & 25 \\
\hline $18-25$ & 9 & 22.5 \\
\hline $26-33$ & 8 & 20 \\
\hline $34-41$ & 6 & 15 \\
\hline $42-49$ & 2 & 5 \\
\hline$>49$ & 5 & 12.5 \\
\hline \multicolumn{2}{|c|}{ Table 4. Showing Relation between Cases and Birth } \\
Spacing \\
\hline
\end{tabular}

Prevalence of schizophrenics is more when birth spacing is less than 33 months. Chi-square for linear trend is $1.28, p$ value is 0.25 and odds of getting schizophrenia is 1 with $1^{\text {st }}$ strata, .87 with $2^{\text {nd }}$ strata, .75 with $3^{\text {rd }}$ and .53 with $4^{\text {th }}$ Schizophrenic is common with $1^{\text {st }}$ and $2^{\text {nd }}$ child. Combined prevalence of schizophrenia is more with $1^{\text {st }} 2$ children and risk decreases with subsequent child.

Chi-square for linear trend is 26.372 , $p$ value is 0.05 . Odds of getting schizophrenia is 1 with 1 st strata, .44 with $2^{\text {nd }}$ and .04 with $3^{\text {rd }}$ strata. $\mathrm{P}$ value of $<.05$, hence difference is significant. The prevalence increases with increase in birth order.

\section{DISCUSSION}

Pregnancy burden decreases maternal folate reserves. Prenutritional deficiency of folate is implicated as a cause of schizophrenia based on some studies. Based on some studies that short birth intervals are associated with risk for Schizophrenia. Luc Smits et al $^{1}$ investigated among other factors the age differences between siblings in family h/o 5095 cases. Relative risk is estimated by use of log-linear Poisson regression as compared to intervals of $>45$ months. The schizophrenia ratio is 1.4 upto 15 months, 1.32 for intervals of $15-17$ months, 1.38 for intervals of $18-20$ months and 1.13 for 21 - 26 months. 
Gunaverdana et $\mathrm{al}^{4}$ examined birth interval and schizophrenia in longitudinal population based cohort. Risk is increased by $150 \%$ in those following a pregnancy interval $<6$ months. They told that Folate deficiency may be an important risk factor for schizophrenia. Sorensen $\mathrm{HJ}$ et al ${ }^{5}$ conducted a cohort of 115752 Danish singletons from 1978 - 98 with members followed from $10^{\text {th }}$ birthday until onset of schizophrenia or death. From this study, they told mothers with iron deficiency during pregnancy had 1.6-fold (95\% Confidence Interval 1.16 - 2.15) increased risk for schizophrenia.

Jari K Haukka et al $^{6}$ on 120 Indian patients' cohort most with schizophrenia were born as one $1^{\text {st }} 3$ siblings birth order with no difference between families with one affected person and none with 2 or more affected persons. They told birth spacing is not a major risk in developing schizophrenia.

From the above studies, there is probability that there is an association between birth spacing, early birth orders and schizophrenia with some studies contrary to it. In this study, prevalence of schizophrenia is more when birth space is $<17$ months, combined prevalence of schizophrenia is more when birth spacing < 33 months. Chi-square for linear trend is 1.282 , $P$ value is 0.25 . Odds of getting schizophrenia is 1 with 1 st strata, .87 with 2 nd, .75 with 3 rd and 0.53 with 4 th strata. It is interesting to see that 1 st and 2 nd born are more prone for schizophrenia breakdown, whereas in western studies 7,8 the last born or later half of siblings are more susceptible. The reason for this being in the west with nuclear pattern of families. As older children grow into adulthood they the leave family and looking after young children continues to be with parents and with increased age of parents the care declines. Those in later birth order suffer great stress with higher incidence of schizophrenia.

In the Indians older children are given all possible affection, but when family is faced with stress, death of a parent or when father's income is insufficient the older siblings are exposed to stress, made to carry or share responsibility and burden of family. They suffer privations and renunciation of own aspirations. This is responsible for greater incidence of schizophrenia in 1st and 2nd siblings.

It must be stressed that schizophrenics are not specifically more in earlier birth order. The incidence of other mental illness also may be more in earlier Indian birth order.

\section{Limitation}

Short sample size makes the study slightly weak, as also sample bias.

\section{Summary}

Based on this study of 40 patients diagnosed as schizophrenia under ICD-10 criteria with 40 controls. Schizophrenia is more common if birth spacing is $<17$ months. Schizophrenia is more common in 1st and 2nd birth orders. Winter seasons are associated with increased incidence of schizophrenia.

\section{CONCLUSION}

From this study, the following points are likely to be stressed. Birth spacing $>17$ months has less chances of schizophrenia. Schizophrenia is more common in birth order 1 and 2. If birth spacing is adequate, birth order is less likely to influence outcome of schizophrenics. Health education is essential for adequate birth spacing in low socio-economic group.

\section{REFERENCES}

[1] Smits L, Zielhuis G, Jongbloet P, et al. The association of birth interval, maternal age and season of birth with the fertility of daughters: a retrospective cohort study based on family reconstitutions from nineteenth and early twentieth century Quebec. Paediatr Perinat Epidemiol 1999;13(4):408-20.

[2] Torrey EF, Rawlings RR, Ennis JM, et al. Birth seasonality in bipolar disorder, schizophrenia, schizoaffective disorder and stillbirths. Schizophr Res 1996;21(3):141-9.

[3] Davies G, Welham J, Chant D, et al. A systematic review and meta-analysis of northern hemisphere season of birth studies in schizophrenia. Schizophr Bull 2003;29(3):587-93.

[4] Gunawardana L, Smith GD, Zammit S, et al. Pre conception inter-pregnancy interval and risk of Schizophrenia. Br J Psychiatry 2011;199(4):338-9.

[5] Soresan HJ, Nielsen PR, Pedersen CB, et al. Assosiation between prepartum maternal iron deficiency and offspring risk of schizophrenia: population-based cohort study with linkage of Danish National Registers. Schizophr Bull 2011;37(5):982-7.

[6] Haukka JK, Suvisaari J, Lönnqvist J. Family structure and risk factors for schizophrenia: case sibling study. BMC Psychiatry 2004;4:41.

[7] Brown AS. Prenatal infection a risk factor for Schizophrenia. Schizophr Bull 2006;32(2):200-2.

[8] Messias E, Kirkpatrick B, Bromet E, et al. Summer birth and deficit schizophrenia: a pooled analysis from 6 countries. Arch Gen Psychiatry 2004;61(10):985-9. 